\title{
Detección de Leishmania sp. en Rattus rattus de la ciudad de Corrientes, Argentina
}

\section{Detection of Leishmania sp. in Rattus rattus in the city of Corrientes, Argentina}

\author{
RM Ruiz ${ }^{\text {a* }}$, CE Bastiania ${ }^{\mathrm{a}}$ MB De Biasio ${ }^{\mathrm{b}}$, EA Alegre $^{\mathrm{a}}$, NN Ramírez ${ }^{\mathrm{a}}$ \\ ${ }^{a}$ Cátedra Salud Pública, Facultad de Ciencias Veterinarias, Universidad Nacional del Nordeste, Corrientes, Argentina.

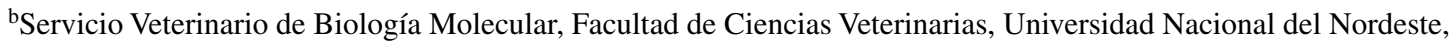 \\ Corrientes, Argentina.
}

\begin{abstract}
SUMMARY
Leishmaniasis is an important public health problem in tropical and subtropical countries worldwide. The identification of natural hosts of Leishmania is fundamental to better understand the epidemiology of the disease. The importance of rodents as reservoir hosts for different Leishmania species have already been described in different countries, however there are not reports of this situation in Argentina. The aim of this work was to capture rodents in the city of Corrientes, Argentina and detect Leishmania spp. in spleens of rodents through molecular analysis using nested PCR (Polymerase Chain Reaction) technical and by light microscopy to detect amastigotes. The results showed that sixty four rodents were collected, sixty three of them were identified as Rattus rattus and only one as Mus musculus. Positive results were obtained by Nested PCR, Leishmania DNA was detected in $43.7 \%$ of 64 tissue samples (first round of nested PCR), 46.8\% (second round of nested PCR) and 3.1\% by light microscopy. This is the first report of its kind where synanthropic rodents were found to be naturally infected by Leishmania spp. in Corrientes city, Argentina. Further studies are needed to evaluate other organs and to differentiate Leishmania species.
\end{abstract}

Key words: rodent, Leishmania, PCR, microscopy.

\section{RESUMEN}

La leishmaniasis es un importante problema de salud pública en ciudades tropicales y subtropicales de todo el mundo. La identificación de reservorios naturales de Leishmania es fundamental para el mejor entendimiento de la epidemiología de la enfermedad. La importancia de roedores como reservorios de diferentes especies de Leishmania ya fue descrita en diferentes ciudades, sin embargo no hay registro de esta situación en Argentina. El principio de este trabajo fue capturar roedores en la ciudad de Corrientes, Argentina, y detectar Leishmania sp. en bazos de roedores mediante análisis molecular por técnica de PCR (reacción en cadena de la polimerasa) anidada y por microscopía óptica para detectar amastigotes. Los resultados mostraron que sesenta y cuatro roedores fueron capturados, sesenta y tres fueron identificados como Rattus rattus y solamente uno como Mus musculus. Se obtuvieron resultados positivos por la técnica de PCR anidada, ADN de Leishmania fue detectado en 43,7\% de 64 muestras de tejido (primera ronda de PCR anidada), 46,8\% (segunda ronda de PCR anidada) y 3,1\% por microscopía óptica. Este es el primer reporte de este tipo en que se hallaron roedores sinantrópicos infectados naturalmente por Leishmania sp. en la ciudad de Corrientes, Argentina. Más estudios son necesarios para evaluar otros órganos e identificar especies de Leishmania.

Palabras clave: roedores, Leishmania, PCR, microscopía.

\section{INTRODUCCIÓN}

La leishmaniasis es una enfermedad producida por la infección de una variedad de Leishmania sp., parásito protozoario de la familia Trypanosomatidae, cuya principal característica estructural es la de poseer kinetoplasto (orden Kinetoplastida) (Cuba Cuba 2000). En la actualidad la leishmaniasis es considerada por la Organización Mundial de la Salud como una enfermedad emergente a nivel mundial, donde la incidencia ha crecido notablemente y se produjo la aparición de nuevas áreas

Aceptado: 19.03.2015.

Sargento Cabral 2139, Corrientes (3400), Argentina; raquel_monicaruiz@hotmail.com endémicas (Ministerio de Salud de la Nación 2012). Es una enfermedad que afecta al hombre y a un gran número de animales silvestres, como marsupiales (Arias et al 1981, Santiago et al 2007), roedores (Braga et al 1991), animales domésticos, principalmente caninos pero también se ha demostrado su presencia en equinos y asnos (Herrer 1999). Existe una gran variedad de vectores pertenecientes a los géneros Phlebotomus y Lutzomyia en el viejo y nuevo mundo, respectivamente, capaces de transmitir el parásito y numerosos mamíferos que pueden actuar como reservorios, por tanto la situación epidemiológica es muy compleja (Laison 1983). En el control de esta parasitosis la vigilancia epidemiológica constituye una actividad fundamental para identificar variadas cadenas epidemiológicas compuestas por diferentes huéspedes mamíferos (Sabroza 2005, Quaresma 
et al 2011) y vectores transmisores (Perez-Doria et al 2008), datos elementales para la aplicación de eficientes planes de control. En el estudio epidemiológico de la Leishmania es indispensable conocer los reservorios domésticos y silvestres para poder analizar y determinar la forma en que se mantiene el agente etiológico en la naturaleza, como así también la manera de presentación de esta enfermedad en diferentes áreas geográficas y en sus distintas presentaciones clínicas. Sin embargo, no es fácil determinar el rol que cumplen los animales en la naturaleza dentro de la cadena epidemiológica y hasta qué punto se pueden convertir en una fuente importante de infección para el hombre y otros animales, o convertirse en verdaderos reservorios ${ }^{1}$. Ante esta situación, es elemental la elección del tipo de muestra y la adecuada obtención de la misma de acuerdo con la especie animal y al objetivo de estudio, clínico o epidemiológico, como también una correcta aplicación del método de diagnóstico (Roque Rodrígues et al 2010). Estas características a tener en cuenta en el momento de determinar el tipo de estudio, conjuntamente con datos ecoepidemiológicos, colaboran en un análisis e interpretación eficiente de los resultados hallados que hacen a la identificación de un verdadero reservorio de Leishmania en un ecosistema determinado. En el nordeste de Argentina existen provincias con presentación endémica de leishmaniasis cutánea, como Chaco, Formosa, Corrientes, en esta última, los casos en humanos se presentan en la ciudad capital y en numerosos departamentos del interior ${ }^{2}$. Si bien los casos de leishmaniasis visceral en humanos en la provincia de Corrientes son escasos (Salomón et al 2012), existe una importante población canina con diagnóstico positivo a este tipo de Leishmania, datos registrados en la Dirección de zoonosis de la provincia de Corrientes. Hasta el momento no existen trabajos en la provincia de Corrientes, incluso en todo el territorio argentino, que corroboren la infección natural de roedores con Leishmania sp., y considerando la numerosa bibliografía acerca del tema que existe en otros países latinoamericanos como Brasil (Laison and Shaw 1973, Laison et al 1981, Oliveira et al 2005) y Perú (Braga Vela et al 1991), entre otros, nos planteamos como objetivo investigar la probabilidad de la existencia de infección natural por Leishmania sp. en roedores que habitan la ciudad de Corrientes en el ámbito urbano por medio del diagnóstico por microscopía óptica y biología molecular, para más tarde realizar estudios que identifiquen su rol dentro de la cadena epidemiológica de

1 Medina R. 1996. Leishmaniasis Experimental en Animales Silvestres. Dermatología Venezolana. Cátedras de Medicina Tropical y Dermato-Sifilografía 5, 91-119. Disponible en:http://svdcd.org.ve/ revista//1966/Web/DV-1-1966-leishmaniasis.pdf.

2 Borda CE, MJF Rea, JR Rosa. Diagnóstico y tratamiento de Leishmaniasis Tegumentaria Americana en el Nordeste Argentino. Comunicaciones Científicas de Ciencia y Técnica. Universidad Nacional del Nordeste 2002. Disponible en: www.unne.edu.ar/ unnevieja/Web/cyt/2002 la enfermedad. Para este objetivo también se trabajó con la búsqueda de condiciones óptimas para la aplicación de técnicas de biología molecular en nuestro laboratorio.

\section{MATERIAL Y MÉTODOS}

\section{ÁREA DE TRABAJO}

El área de estudio se estableció en zona periurbana en barrios localizados a orilla del río Paraná, costanera Norte de la ciudad de Corrientes, Argentina, en el extremo noroccidental de la provincia de Corrientes $\left(27^{\circ} 28^{\prime} \mathrm{S}\right.$ y $58^{\circ} 50^{\prime} \mathrm{O}$ ). La distribución de viviendas en el área de estudio es marcadamente heterogénea, con una amplia variabilidad en la relación de viviendas por manzana. Esta zona de estudio se encuentra bordeada por el río Paraná con presencia de importantes zonas de vegetación, humedad y presencia de colchones de hojarascas permanentes en el suelo por la diversidad arbórea, estas características confieren un hábitat especial para el desarrollo de Lutzomyia sp., vector que fue identificado en la zona urbana y periférica de la ciudad de Corrientes (Salomón et al 2008). Por lo demás, los barrios que se encuentran más cercanos a la costa ribereña no poseen urbanización, por tanto es frecuente el acúmulo de basura y la reproducción de roedores. También es una zona donde se detectaron numerosos casos de leishmaniasis visceral y en menor grado leishmaniasis cutánea en caninos, datos no publicados pero registrados en la Dirección de Zoonosis de la Municipalidad de la ciudad de Corrientes. Debido a que no existen antecedentes previos, la suma de todas estas características llevó a la elección del área de trabajo en esta primera etapa de estudio.

\section{CAPTURA DE ROEDORES Y TOMA DE MUESTRAS}

Este trabajo fue desarrollado durante los años 2011 y 2012 teniendo en cuenta criterios éticos de bienestar animal (actividades que se desprenden de un proyecto mayor aprobado por el comité de ética de la Facultad de Ciencias Veterinarias UNNE. Expediente No: 14-201102038- $\mathrm{N}^{\mathrm{o}}$ protocolo 0010). Para la captura de roedores el área se dividió en 47 unidades de muestreo. Las jaulas fueron entregadas a pobladores en número de dos a tres por manzana por día, rotando estas por viviendas hasta cubrir un máximo de $80 \%$ de las viviendas del área de estudio, teniendo en cuenta que el área de estudio abarca 4.225 parcelas, datos obtenidos del registro de la Municipalidad de la ciudad de Corrientes. La relación vivienda por manzana es variable por ser de distribución muy heterogénea.

Se utilizaron para la captura de animales vivos jaulas tipo Sherman. El cebo colocado en ellas consistió en semillas de zapallo o grasa bovina. Las jaulas fueron dispuestas de acuerdo con la identificación de rastros hallados previamente o información suministrada por los 
pobladores. El control de captura se realizó diariamente. Los ejemplares que quedaron atrapados fueron trasladados al Laboratorio de la Cátedra de Salud Pública de la Facultad de Ciencias Veterinarias de la Universidad Nacional del Nordeste (UNNE), donde se procedió a la identificación por género y especie según clave de Osgood (1943) y a la observación clínica de los animales para detectar lesiones compatibles con leishmaniasis.

Los animales se sujetaron y anestesiaron con hidrato de cloral al 20\% siguiendo las normas internacionales de bienestar animal, se realizó la eutanasia y se extrajeron diferentes fluidos y órganos para ser sometidos al diagnóstico de Leishmania. Este trabajo se inicia con la aplicación de dos técnicas diagnósticas en bazos de los roedores por su importancia en la localización de Leishmania visceral y también cutánea en este órgano, ya citada por otros autores (Braga Vela et al 1999, Roque Rodríguez et al 2010).

\section{TÉCNICAS DIAGNÓSTICAS UTILIZADAS}

Microscopía óptica. Con el bazo extraído se realizaron extendidos citológicos que fueron coloreados con la tinción de Giemsa. Los preparados se fijaron con alcohol metílico durante tres minutos, luego del secado fueron coloreados con una solución de giemsa de 1 parte del colorante en 9 de agua destilada durante 10 minutos, luego fueron lavados con abundante agua y se dejaron secar. La observación en microscopio óptico se realizó con objetivo de inmersión $(100 \mathrm{X})$ en busca de amastigotes. Muestras del mismo órgano se conservaron a $-20^{\circ} \mathrm{C}$ para aplicar métodos diagnósticos moleculares específicos.

\section{BIOLOGÍA MOLECULAR}

Extracción de ADN mediante digestión con CTAB. La extracción de ADN se llevó a cabo a partir de muestras de tejido de bazo conservadas a $-20{ }^{\circ} \mathrm{C}$ e identificadas en tubos eppendorf. Estas fueron fraccionadas con bisturí sobre placas de Petri, trasvasadas a un nuevo tubo y resuspendidas en $500 \mu \mathrm{l}$ de solución fisiológica. Luego de agitar con vórtex se centrifugaron durante 4 minutos a $12.000 \mathrm{rpm}$ (Microcentrífuga Spectrafuge 24D Labnet Internacional), se eliminó el sobrenadante y se agregaron $700 \mu \mathrm{l}$ de solución de homogenización conteniendo CTAB (Bromuro de cetil trimetil amonio) incubando a Baño María durante 2 horas a $60^{\circ} \mathrm{C}$. Seguidamente se agregaron $700 \mu \mathrm{l}$ de cloroformo: alcohol isoamílico (24:1), se centrifugaron a $12.000 \mathrm{rpm}$ durante 3 minutos y se trasvasó a un tubo nuevo la fase superior acuosa, la que contiene el ADN. Se realizó la precipitación agregando $700 \mu \mathrm{l}$ de alcohol isopropílico frío, incubando a $-20{ }^{\circ} \mathrm{C}$ durante 30 minutos y centrifugando 10 minutos a $13.000 \mathrm{rpm}$. El precipitado se lavó con $1.000 \mu \mathrm{l}$ de etanol al $70 \%$, se centrifugó 5 minutos a 13.000 rpm, se descartó el sobrenadante y se resuspendió el material en $30 \mu \mathrm{l}$ de agua estéril conservando en freezer a $-20{ }^{\circ} \mathrm{C}$ hasta el momento de su utilización.
PCR control de material genético de ratas. Con el fin de comprobar la presencia de ADN amplificable (buena calidad) y ausencia de inhibidores luego de la extracción a partir de las muestras se desarrolló una reacción de amplificación utilizando iniciadores dirigidos a material genético que debería estar presente en los mismos. Dichos iniciadores (Walker et al 2004) son específicos para una porción no codificante y conservada de genoma de rata, ratón y hámster y generan amplificaciones de 118 pb. Este control es de gran importancia en los casos en los que las reacciones de amplificación para Leishmania dieron no detectable.

La reacción de amplificación se realizó en un volumen final de $25 \mu \mathrm{l}$ empleando como molde ADN de tejido de bazo de cada uno de los animales muestreados y conteniendo las siguientes concentraciones finales de reactivos: $1 \mathrm{X}$ de buffer de PCR, 1,5mM $\mathrm{MgCl}_{2}, 0,2 \mathrm{mM}$ de cada uno de los $\mathrm{dNTP}_{\mathrm{S}}, 0,2 \mathrm{mM}$ de cada iniciador y $1 \mathrm{U}$ de Taq DNA polimerasa. Se incluyeron un control positivo y un control negativo consistente en $\mathrm{ADN}$ de ratas y agua.

El programa de ciclado incluyó las siguientes etapas: desnaturalización inicial a $95^{\circ} \mathrm{C}$ durante un minuto seguida de 30 ciclos de amplificación (desnaturalización a $95{ }^{\circ} \mathrm{C}$ por 30 segundos, hibridización a $55^{\circ} \mathrm{C}$ por 30 segundos y extensión a $72^{\circ} \mathrm{C}$ por 30 segundos) y extensión final a $72{ }^{\circ} \mathrm{C}$ por 4 minutos e incubación a $4{ }^{\circ} \mathrm{C}$. Los productos de PCR se separaron por electroforesis en geles de agarosa al $1 \%$ en buffer TBE 1X (Tris- Ácido bórico- EDTA), teñidos con bromuro de etidio y visualizados por transiluminación UV.

PCR para leishmania: PCR anidada aplicada a la detección de genomas de Leishmania sp. La PCR anidada utilizada comprende dos rondas de amplificación para detectar ADN de protozoos del género Leishmania sp. En la primera ronda se utilizaron los iniciadores externos $\mathrm{S} 4 \mathrm{y}$ S12 (Uliana et al 1994) que amplifican una región del gen de una subunidad menor de ARNr y genera fragmentos de 520 pares de bases (pb). La segunda ronda de amplificación incrementa la sensibilidad y especificidad de la detección y utiliza los iniciadores internos S17 y S18 (Savani et al 2010) generando amplificaciones de $490 \mathrm{pb}$. Como control positivo se utilizó ADN de Leishmania chagasi cedido gentilmente por el Instituto Nacional de Parasitología "Dr. Mario Fatala Chaben", Argentina, y agua destilada como control negativo. Para ambas rondas se realizaron reacciones propuestas por Uliana et al (1994), conteniendo las siguientes concentraciones finales de reactivos: $1 \mathrm{X}$ de buffer de PCR, 2,0 mM MgCl $2,0,2 \mathrm{mM}$ de cada dNTP ${ }_{\mathrm{S}}$, $0,2 \mu \mathrm{M}$ de cada iniciador y 2,0 U de Taq DNA polimerasa, en un volumen total de $20 \mu \mathrm{l}$. Para la primera ronda se utilizó $2 \mu \mathrm{l}$ de ADN problema y para la segunda ronda 1 $\mu \mathrm{l}$ del producto de amplificación de esta primera PCR.

El programa de ciclado para la primera ronda fue el siguiente: desnaturalización inicial a $94{ }^{\circ} \mathrm{C}$ durante 3 minutos, seguida de 35 ciclos consistentes en desnaturalización a $94{ }^{\circ} \mathrm{C}$ por 60 segundos, hibridización a $50{ }^{\circ} \mathrm{C}$ por 
60 segundos y extensión a $72{ }^{\circ} \mathrm{C}$ por 60 segundos finalizando con una extensión final a $72{ }^{\circ} \mathrm{C}$ por 7 minutos e incubación a $4{ }^{\circ} \mathrm{C}$. Mientras que para la segunda ronda se aplicó el siguiente programa: desnaturalización inicial a $94{ }^{\circ} \mathrm{C}$ durante 4 minutos, seguido de 35 ciclos consistentes en desnaturalización a $94{ }^{\circ} \mathrm{C}$ por 60 segundos, hibridización a $59{ }^{\circ} \mathrm{C}$ por 60 segundos y extensión a $72{ }^{\circ} \mathrm{C}$ por 30 segundos finalizando con una extensión final a $72^{\circ} \mathrm{C}$ por 10 minutos e incubación a $4{ }^{\circ} \mathrm{C}$.

Los productos de PCR fueron separados por electroforesis en geles de agarosa al $2 \%$ y buffer TBE1X, teñidos con bromuro de etidio y visualizados por transiluminación UV. Se utilizó un marcador de peso molecular (Ladder 100) para la comparación de tamaños de los fragmentos amplificados.

Todas las secuencias de los iniciadores utilizados para las distintas PCR pueden observarse en el cuadro 1.

\section{RESULTADOS Y DISCUSIÓN}

\section{CAPTURA E IDENTIFICACIÓN DE ROEDORES}

Se capturaron 64 roedores y se procesó el mismo número de muestras de bazo para ambas técnicas. Se logró identificar el 100 por ciento de los animales procesados, donde 63 individuos fueron clasificados dentro del género Rattus y solo un ejemplar correspondió a la especie Mus musculus.

Las especies y subespecies identificadas dentro del género Rattus fueron 44 individuos para Rattus rattus rattus, 8 para Rattus rattus alexandrinus y 11 para Rattus rattus frugivorus. A la inspección clínica ningún animal capturado presentó lesiones compatibles con leishmaniasis.

\section{MICROSCOPÍA ÓPTICA}

A la lectura del total de los extendidos citológicos se pudo detectar solo dos muestras positivas $(3,1 \%)$ con presentación de muy baja densidad por campo (figura 1).

DETECCIÓN MEDIANTE TÉCNICAS DE BIOLOGÍA MOLECULAR

PCR control de material genético de ratas. Como resultado en las PCR control, se logró observar en todas las muestras bandas de amplificación de un fragmento de $118 \mathrm{pb}$ indicando presencia e integridad de material genético y ausencia de inhibidores de la reacción de la especie estudiada con una correcta obtención de ADN.

Aplicación de PCR anidada en la detección de Leishmania sp. Se optimizaron las condiciones químicas y térmicas para la PCR anidada. Si bien la concentración de geles de agarosa varía según los diferentes autores, nosotros logramos optimizar la detección en geles al $2 \%$ para ambas corridas de amplificación.

En la detección de genomas de Leishmania se aplicó la técnica PCR anidada al 100\% de las muestras. Se detectó en la primera ronda de PCR amplificación específica de ADN de Leishmania sp. en 28 muestras (43,7\%) (figura 2). En la aplicación de la segunda ronda de PCR más específica se logró confirmar la detección para Leishmania sp. en las mismas muestras (figura 3) y a estas se sumaron dos muestras más que fueron detectadas en la primera ronda como sospechosas por presentar bandas poco nítidas pero confirmadas en una segunda instancia, por lo que se detectó la amplificación de bandas correspondientes a Leishmania sp. en 30 muestras $(46,8 \%)$. Es importante aclarar que las dos muestras que resultaron positivas por microscopía óptica también resultaron positivas por PCR anidada. En ambas reacciones moleculares no hubo presencia de amplificación en controles negativos.

Del total de muestras procesadas, las que resultaron positivas se distribuyeron según especie de roedor de la siguiente manera: para Rattus rattus rattus $6,6 \%$ $(\mathrm{n}=2)$ mediante microscopía óptica y 76,6\% (n=23) mediante PCR anidada. Muestras de Rattus rattus alexandrinus fueron positivo en $16,6 \%(n=5)$ mediante PCR anidada y con esta misma técnica resultaron positivas muestras de Rattus rattus frugivorus en $6,6 \%(\mathrm{n}=2)$.

La ecoepidemiología de la leishmaniasis es muy variable dependiendo del tipo de reservorios, clase de Leishmania y cadena epidemiológica que se cumple en un medio ambiente. Si bien se conoce que los roedores son reservorios de Leishmania (Acha y Szyfres 2003), es importante verificar que esta situación se cumpla en diferentes ambientes, identificar las especies de reservorios, clase de Leishmania que albergan estos animales y qué papel juegan dentro de la cadena epidemiológica en una región determinada.

Cuadro 1. Características de los iniciadores utilizados para las reacciones de PCR.

Characteristics of the primers used for PCR reactions.

\begin{tabular}{lrc}
\hline Iniciadores & Secuencia de iniciadores utilizado & Amplificación \\
\hline Secuencia S4 & Fw 5'- GAT CCA GCT GCA GGT TCA CC -3' & $520 \mathrm{pb}$ \\
Secuencia S12 & Rev 5'- GGT TGA TTC CGT CAA CGG AC - 3' \\
Secuencia S17 & Fw 5'- CCA AGC TGC CCA GTA GAA T -3' & \\
Secuencia S18 & Rev 5'- TCG GGC GGA TAA AAC CC - 3' \\
mouse & Fw 5'- AGA TGG CTC AGT GGG TAA AGG -3' & $490 \mathrm{pb}$. \\
& Rev 5'- GTG GAG GTC AGA GGA CAA ACT T- 3' & $118 \mathrm{pb}$. \\
\hline
\end{tabular}




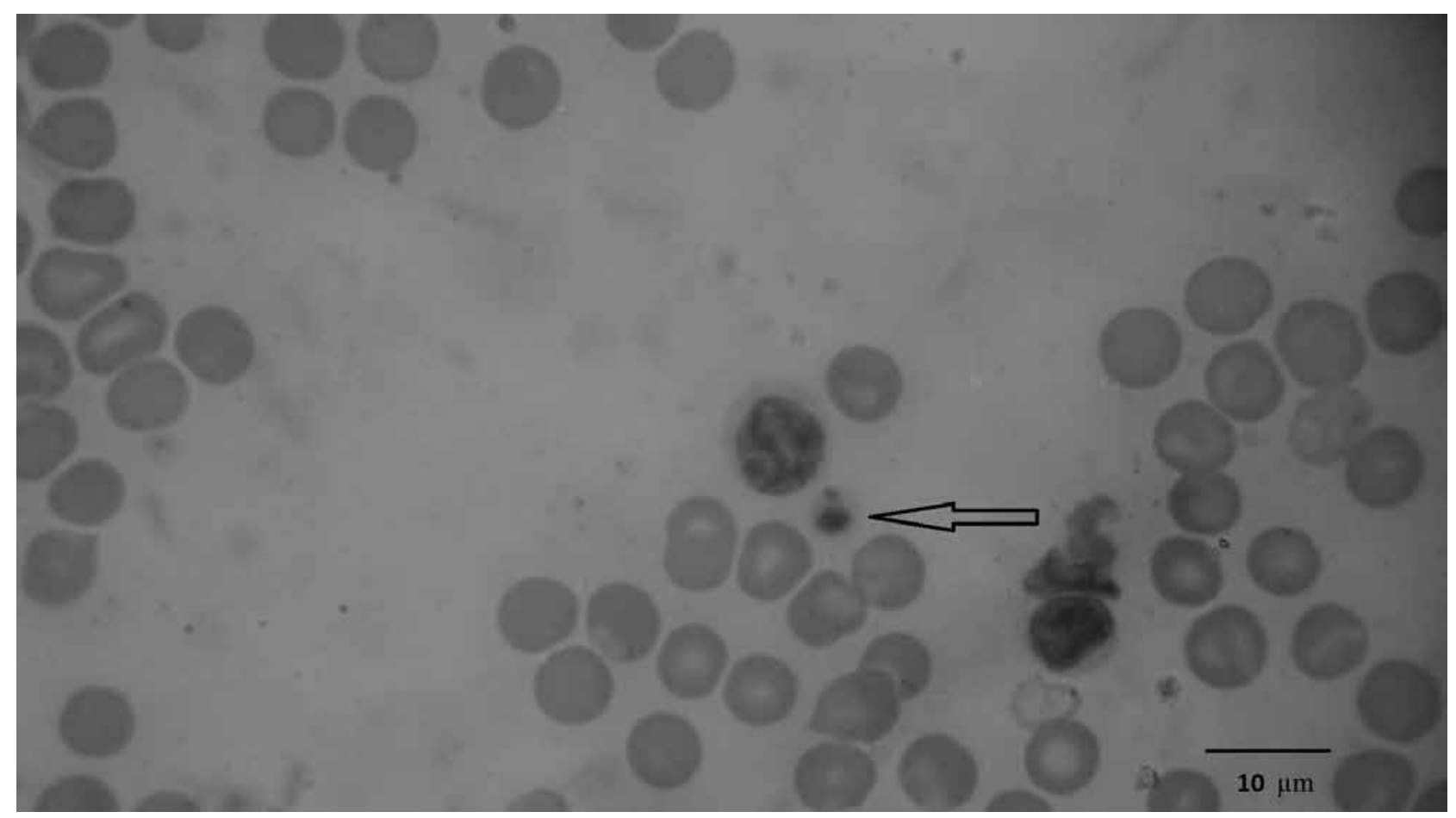

Figura 1. Microscopía óptica. Extendido citológico de bazo. Coloración Giemsa (100X). Flecha indica amastigote. Optical microscopy. Cytological extended spleen. Giemsa Staining (100X). Arrow indicates amastigote.

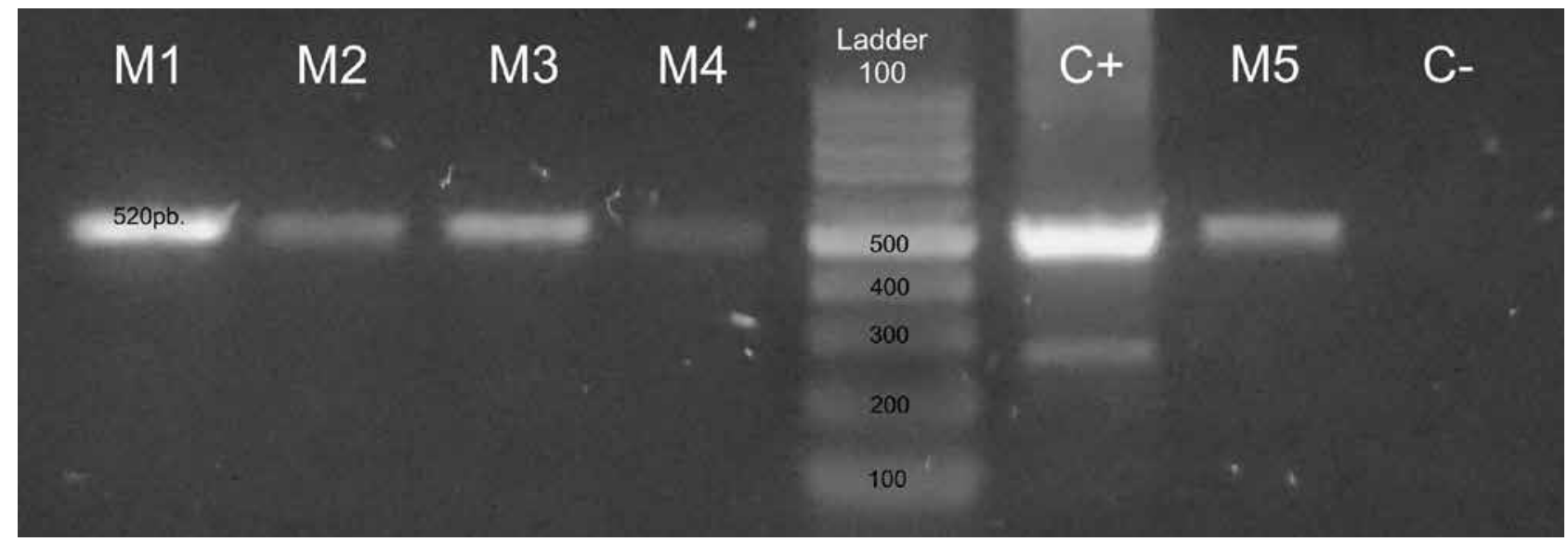

Figura 2. PCR anidada. Primera ronda. Muestras positivas con bandas de amplificación de 520 pb (M1, M2, M3, M4, M5). Marcador de peso molecular (Ladder 100). Control positivo (C+) y control negativo (C-).

Nested PCR. First round. Positive samples amplified bands in 520 pb (M1, M2, M3, M4, M5). Molecular weight marker (Ladder 100). Positive Control (C+) and negative control (C-).

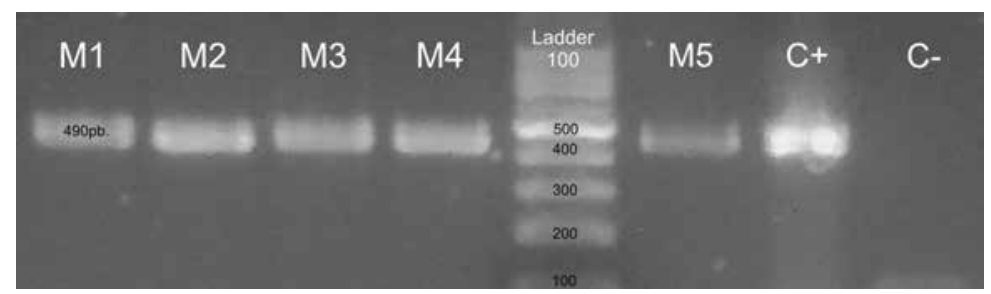

Figura 3. PCR anidada. Segunda vuelta. Muestras positivas con bandas de amplificación de 490 pb (M1, M2, M3, M4, M5). Marcador de peso molecular (ladder 100). Control positivo (C+) y control negativo (C-).

Nested PCR. Second round. Positive samples amplified bands of 490 bp. (M1, M2, M3, M4, M5). Molecular weight marker (100 ladder). Positive Control $(\mathrm{C}+)$ and negative control (C-). 
Es así que roedores silvestres que habitan Perú, como especies del género Proechimys, resultaron ser positivos al diagnóstico por técnicas de cultivo de tejido hepático y también por caracterización de patrones isoenzimáticos donde se identificó Leishmania braziliensis braziliensis (Braga Vela et al 1991), lo que demuestra que el agente etiológico que causa la leishmaniasis cutánea pueden asentarse en órganos internos de roedores con mayor frecuencia que en otras especies animales sin presentar manifestaciones clínicas visibles. Con nuestros resultados también confirmamos un asentamiento del parásito en órganos internos como lo es el bazo de roedores. Hasta el momento dentro de la inspección clínica de los animales procesados en nuestro trabajo se destaca la ausencia de lesiones compatibles con leishmaniasis, coincidiendo con los resultados de Braga Vela et al 1991, donde los animales que resultaron positivos tampoco manifestaron lesiones visibles. También Laisson et al (1981) mencionan en los resultados de sus estudios la infección de roedores con presentación comúnmente inaparente. Esta característica ya había sido informada por Laison y Shaw (1973) cuando en 21 Proechimys guyannensis que habitaban la cuenca del Amazonas lograron aislar Leishmania mexicana amazonensis y cuyas pieles poseían un aspecto normal, sin lesiones cutáneas detectables. Esta característica debe tenerse en cuenta al momento de seleccionar los animales para su estudio, debido a que no todo animal sin síntomas visibles debería ser descartado para el diagnóstico; así también mediante ensayos experimentales realizados en Thrichomys laurentius se demostró que Leishmania infantum y L. braziliensis tienen capacidad de invadir y mantenerse en las vísceras sin manifestar evidencia clínica de la infección en la piel (Rodríguez Roque et al 2010). La técnica de PCR anidada utilizada en este trabajo demostró una alta sensibilidad debido a que comprende dos rondas de amplificación con distintos pares de iniciadores en cada reacción, una se realiza con iniciadores externos para amplificar una región de ADN más extensa, y luego, con el producto de amplificación obtenido, se ejecuta una segunda amplificación con los iniciadores internos para amplificar la región específica. Además, si se compara esta técnica con microscopía de extendidos citológicos teñidos con giemsa realizados con muestras del mismo órgano para el diagnóstico de Leishmania sp., se puede corroborar su alta sensibilidad demostrada por los resultados obtenidos en este trabajo, donde el número de muestras positivas detectadas por biología molecular fueron marcadamente mayor respecto de las halladas por microscopía óptica, estas últimas también detectadas por PCR. Esta misma técnica de biología molecular anidada fue utilizada para identificar este parásito en otra clase de roedores como Rhombomys opimus (Rodentia: Gerbillinae) de Irán, donde los resultados mostraron también una alta sensibilidad de la técnica con una tasa de infección a Leishmania sp. de $55,8 \%$, es decir, que hallaron positivos 29 de los 52 jerbos analizados (Akhavan et al 2010). La reacción en cadena de la polimerasa (PCR) es, sin duda, un gran avance para el diagnóstico de la infección por Leishmania sp., teniendo en cuenta que es muy adecuada para este tipo de trabajo, donde la detección de infecciones naturales en animales, a veces, es muy baja y su alta sensibilidad permite detectarla.

En cuanto a la prevalencia hallada podríamos afirmar que los resultados obtenidos demuestran una elevada prevalencia, en concordancia con resultados obtenidos en roedores capturados en Minas Gerais, Brasil, de ratas silvestres y sinantrópicas, donde Rattus rattus y Trichomys apereoides fueron las especies que presentaron la más alta prevalencia de infección natural diagnosticadas por técnicas de biología molecular comparadas con especies silvestres como Oryzomys subflavus, Galea spixii, Bolomys lasiurus y Wiedomys pyrrhorhinos (Oliveira et al 2005). Trabajos realizados por Alexander et al (1998) demostraron también la importancia de la presencia de Leishmania sp. en la especie $R$. rattus mediante técnicas de hibridación por PCR.

Los resultados aquí expuestos abren un nuevo panorama de estudio en nuestra región, debido a que si bien la infección natural de roedores por Leishmania ya fue comprobada en otras partes del mundo (Brandão-Filho et al 2003, De Lima et al 2002, Van Wynsberghe et al 2000), hasta el momento no existían resultados de estudios que así lo confirmen en roedores de la provincia de Corrientes, Argentina, sumando a estos resultados la importancia de hallarlos en animales no domésticos, específicamente en roedores sinantrópicos que conviven en estrecho contacto con el hombre. Por tanto, el siguiente paso es identificar las diferentes especies de Leishmania y más tarde determinar el papel real que juegan estos roedores dentro de la cadena epidemiológica de la enfermedad en nuestra región.

\section{REFERENCIAS}

Acha PN y B Szyfres. 2003. Zoonosis y enfermedades transmisibles comunes al hombre y a los animales. Parasitosis. Vol. III. $3^{\mathrm{a}}$ ed. Ed. OPS-OMS, Washington DC, USA, Pp 53-64.

Akhavan AA, MR Yaghoobi-Ershadi, A Khamesipour, H Mirhendi, MH Alimohammadian, Y Rassi, MH Arandian, R Jafari, H Abdoli, N Shareghi, M Ghanei, N Jalali-zand. 2010. Dynamics of Leishmania infection rates in Rhombomys opimus (Rodentia: Gerbillinae) population of an endemic focus of zoonotic cutaneous leishmaniasis in Iran. Bull Soc Pathol Exot 103, 84-9.

Alexander B, C Lozano, DC Barker, SHE McCann, GH Adler. 1998. Detection of Leishmania (Viannia) braziliensis complex in wild mammals from Colombian coffee plantations by PCR and DNA hybridization. Acta Trop 69, 41-50.

Arias JR, RD Naiff, MA Miles, AA De Souza. 1981. The oposum, Didelphis marsupialis (Marsupialia: Didelphidae) as a reservoir host of Leishmania brasilensis guayanensis in the Amazon Basin of Brasil. Trans R. Soc Trop Med Hyg 75, 537-541.

Braga Vela J, E García Martínez, M Viena del Águila, R Braga Ribeiro. 1991. Aislamiento de Leishmania brazilienzis braziliensis en Proechimys sp. capturado en el río Napo, Loreto-Perú. Folia Amazónica IIAP 3, 129-138.

Brandão-Filho SP, ME Brito, FG Carvalho, EA Ishikawa, E Cupolillo, L Floeter-Winter, JJ Shaw. 2003. Wild and synanthropic hosts of Leishmania (Viannia) braziliensis in the endemic cutaneous 
leishmaniasis locality of Amaraji, Pernambuco State, Brazil. Trans $R$ Soc Trop Med Hyg 97, 291-296.

Cuba CA. 2000. Diagnóstico parasitológico de la leishmaniasis tegumentaria americana. Rev Med Exp 17, 39-52.

De Lima H, Z De Guglielmo, A Rodríguez, J Convit, N Rodriguez. 2002. Cotton rats (Sigmodon hispidus) and black rats (Rattus rattus) as possible reservoirs of Leishmania spp. in Lara State, Venezuela. Mem Inst Oswaldo Cruz 97, 169-174.

Herrer A. 1999. La leishmaniasis tegumentaria en el Alto Tambopata, Departamento de Puno, Perú. Rev Perú Med Exp Salud Pública 16, 15-24.

Lainson R, JJ Shaw. 1973. Leishmania and leishmaniasis of the New World, with particular reference to Brazil. Bull Pan Am Health Org 7, 1-19.

Lainson R, JJ Shaw, PD Ready, MA Miles, M Próvoa. 1981. Leishmaniasis in Brazil: XVI: Isolation and identiflcation of Leishmania species from sandflies, wild animmals and man in noth Pará State, with particular reference to L. braziliensis guyanensis causative agent of "pian bois". Trans of the Royal Soc of Trop Med and Hyg 75, 530-536.

Lainson R. 1983. The American Leishmaniases: some observations on their ecology and epidemiology. Trans R Soc Trop Med Hyg 77, 569-596.

Ministerio de Salud de la Nación, República Argentina. 2012. Programa Nacional de Control de enfermedades Zoonóticas. Ministerio de Salud de la Nación, Buenos Aires, Argentina.

Oliveira FS, C Pirmezb, MQ Piresa, RP Brazilc, RS Pachecoa. 2005. PCR-based diagnosis for detection of Leishmania in skin and blood of rodents from an endemic area of cutaneous and visceral leishmaniasis in Brazil. Vet Parasitol 129, 219-227.

Osgood WH. 1943. The mammals of Chile. Field Museum of Natural History, Chicago. Zoological Series 30.

Pérez-Doria A, E Bejarano, D Sierra, I Vélez. 2008. Caracteres moleculares para la determinación taxonómica de tres especies de Lutzomyia, vectores potenciales en el Valle de Aburrá, Colombia. Rev Soc Entomol Argent 67, 99-108.

Quaresma PF, FD Rêgo, HA Botelho, SR Da Silva, AJ Moura Júnior, RG Teixeira Neto, FM Madeira, MB Carvalho, AP Paglia, MN Melo, CM Gontijo. 2011. Wild synanthropic and domestic hosts of Leishmania in an endemic area of cutaneous leishmaniasis in Minas Gerais State, Brazil. Trans R Soc Trop Med Hyg 105, 579-85.

Roque Rodrigues AL, E Cupolillo, RS Marchevsky, AM Jansen. 2010. Thrichomys laurentius (Rodentia; Echimyidae) as a putative reservoir of Leishmania infantum and L. braziliensis: patterns of experimental infection. PLoS Negl Trop Dis 4, e589.

Sabroza P. 2005. Vigilância da Leishmaniose Visceral nas Américas a partir da Caracterização de Unidades Territoriais de Relevância Epidemiológica. Consulta de Expertos OPS/OMS sobre leishmaniasis visceral en las Américas. $152 \mathrm{Pp}$.

Salomón OD, LK Ramos, MG Quintana, SA Acardi, MS Santini, A Schneider. 2009. Distribución de vectores de leishmaniasis visceral en la provincia de Corrientes. Medicina (B. Aires) 69, 625-630

Salomón OD, AV Mastrángelo, MS Santini, S Ruvinsky, T Orduna, A Sinagra, C Luna, A Riarte, N Casas, P Amiotti. 2012. Leishmaniasis visceral: senderos que confluyen, se bifurcan. Salud colectiva 8, 49-63.

Santiago ME, RO Vasconcelos, KR Fattori, DP Munari, AF Michelin, VM Lima. 2007. An investigation of Leishmania spp. in Didelphis spp. from urban and peri-urban areas in Bauru (São Paulo, Brazil). Vet Parasitol 150, 283-290.

Savani ES, MF Almeida, MC de Oliveira Camargo, SR D'Auria, MM Sodre Silva, ML de Oliveira, D Sacramento. 2010. Detection of Leishmania (Leishmania) amazonensis and Leishmania (Leishmania) Infantum chagasi in Brazilian bats. Vet Parasitol 168, 5-10.

Uliana SRB, K Nelson, SM Beberley, EP Camargo, LM Floeter-Winter. 1994. Discrimination amongs Leishmania by polymerase chain reaction and hibridization with small subunit ribosomal DNA derived oligonucleotides. J Euk Microbiol 41, 324-330.

Van Wynsberghe NR, SB Canto-Lara, AG Damián-Centeno, MF Itzá-Ortiz, FJ Andrade-Narváez. 2000. Retention of Leishmania (Leishmania) mexicana in naturally infected rodents from the state of Campeche, Mexico. Mem Inst Oswaldo Cruz, 95, 595-600.

Walker JA, DA Hughes, DJ Hedges, BA Anders, ME Laborde, J Shewale, SK Sinha, MA Batzer. 2004. Quantitative PCR for DNA identification based on genome-specific interspersed repetitive elements. Genomics 83, 518-527. 
